\title{
Development and Plasticity of the Corticospinal System in Man
}

\author{
J.A. Eyre \\ Developmental Neurosciences, Department of Child Health \\ University of Newcastle upon Tyne, UK
}

\section{INTRODUCTION}

The young human brain is highly plastic, thus brain lesions occurring during development interfere with the innate development of the architecture, connectivity, and mapping of functions and trigger modifications in structure, wiring, and representations (for review see Payne \& Lomber, 2001). In childhood, the motor cortex and/or the corticospinal tract is a common site of brain damage and the prenatal or immediately perinatal period is the most common time for brain damage to occur. It is now increasingly appreciated that the corticospinal system is capable of substantial reorganization after lesions and such reorganization is likely to underlie the partial recovery of function (Terashima, 1995; Eyre et al., 2001; Eyre et al., 2002). Clearly the developing nervous system has a much greater potential for plasticity, which can involve plasticity not only of the motor areas of the ipsi-lesional cerebral cortex but also of the contralesional cortex, the corticospinal tract, and the spinal cord network (Benecke et al., 1991; Carr et al., 1993; Cao et al., 1994; Lewine et al., 1994; Maegaki et al., 1995; Terashima , 1995; Nirrko et al., 1995; O'Sullivan et al., 1998; Balbi et al., 2000; Eyre et al., 2000a; Eyre et al., 2001). Functional and anatomical evidence demonstrates that spontaneous plasticity can be potentiated by activity and by

Reprint requests to: Prof. J.A. Eyre, Developmental Neurosciences, Department of Child Health, Sir James Spence Institute for Child Health, Royal Victoria Road, Newcastle upon Tyne NE1 4LP, UK; e-mail: j.a.eyre@ncl.ac.uk specific experimental manipulation as well. Knowledge of the time course and processes of corticospinal tract system development and plasticity is essential both for a better understanding of current rehabilitation treatments and for designing new strategies for the treatment of children without sustaining damage to the corticospinal tract system early in life.

\section{CORTICOSPINAL TRACT DEVELOPMENT AND PLASTICITY IN ANIMAL MODELS}

The development of the corticospinal tract system has been studied most extensively in the rat. In the neonatal rat, the corticospinal projection originates from the whole neocortex including the visual cortex (Stanfield et al., 1982; Stanfield \& O'Leary, 1985; Stanfield, 1992). Not all these axons enter the grey matter, those that do initially occupy a larger terminal field and contact more spinal neurons than in the adult (Curfs et al., 1994; 1995; 1996). Massive axon collateral withdrawal coupled with modest corticospinal tract cell death leads to complete elimination of the corticospinal tract projection from regions of the cortex, a reduction in the number of corticospinal axons projecting from primary sensorimotor cortex and associated areas like the premotor cortex (Oudega et al., 1994) and predominant withdrawal of ipsilateral projections (Joosten et al., 1992). Substantial lesions of the sensorimotor cortex or the corticospinal tract in sub-primate mammals early in postnatal life lead to hypertrophy of the 
undamaged motor cortex and the corticospinal tract projection (Hicks \& D'Amato, 1970; 1977; Uematsu et al., 1996). Such changes are associated with the maintenance of an increased ipsilateral corticospinal tract projection from the undamaged hemisphere. The cells of origin of the induced aberrant ipsilateral axons are more widely distributed and distinct from the cells of origin of the crossed or contralateral corticospinal projection (Huttenlocher \& Raichelson, 1989; Reinoso \& Castro, 1989; Stanfield, 1992; Jansen \& Low, 1996). Thus, induced ipsilaterally projecting corticospinal axons from the undamaged cortex do not arise as branches of the contralateral corticospinal projection but rather arise from neurons that extend axons into the ipsilateral spinal cord during development and whose axons would normally be withdrawn. The distribution of aberrant ipsilateral axons within the spinal grey matter resembles that of the contralateral corticospinal projection (McClung \& Castro, 1975; Barth \& Stanfield, 1990) and synaptic contacts have been demonstrated (McClung \& Castro, 1975; Leong, 1976). Ipsilateral forelimb movements are observed following the stimulation of the intact cortex at abnormally low current thresholds and are abolished by medullary pyramidectomy (Kartje-Tillotson et al., 1985; 1987).

\section{CORTICOSPINAL DEVELOPMENT AND PLASTICITY IN MAN}

Studies within our laboratory of embryonic human brain development between 6 and $7 \mathrm{wk}$ postconceptional age (PCA) revealed that the cortical plate is barely formed at that time and no outgrowth of GAP43-positive axons can be detected (Hagan et al., 1999). Surprisingly, the most widely quoted studies of human corticospinal tract development (Humphrey, 1960; O'Rahilly \& Muller, 1994) claim that corticospinal tract axons reach the medulla by 8 wk PCA. Decussation is thought to occur before 15 wk PCA, and corticospinal axons to reach as far as the lumbar enlargement by 18 wk PCA. Remarkably little neuroanatomical work on the developing human corticospinal tract has been done since the original observations.

We recently confirmed that human corticospinal axons reach the lower cervical spinal cord by 24 weeks PCA at the latest. Following a waiting period of up to a few weeks, they progressively innervate the grey matter such that there is extensive innervation of spinal neurons, including motoneurones before birth (Eyre et al., 2000b; 2002). By 40 wk, PCA corticospinal axons have begun to express neurofilaments and to undergo myelination. The anatomical findings of early corticospinal innervation are confirmed by neurophysiological studies demonstrating that functional synaptic corticospinal projections to motoneurones and to spinal interneurons are established prenatally during the final trimester of pregnancy (Eyre et al., 2000b). The combined morphological observations provide strong evidence for prenatal establishment of functional corticospinal innervation in man, even though it is not associated with a significant developmental milestone of motor behavior. Rather than furthering motor control per se, this early innervation most likely occurs to allow activity in the corticospinal system as a whole to shape the development of the motor cortex and the spinal motor cen' ${ }^{1}$ rs (Eyre et al., 2000b; 2001).

In the newborn, we demonstrated significant bilateral innervation of spinal motoneuronal pools from each motor cortex. Thus, focal transcranial magnetic stimulation (TMS) of the motor cortex evokes responses in ipsilateral and contralateral muscles that have similar thresholds and amplitudes but shorter onset latencies ipsilaterally, consistent with the shorter ipsilateral pathway length (Eyre et al., 2001) (Fig. 6A). In longitudinal and crosssectional studies of normal babies and children, neurophysiological findings that are consistent with withdrawal in significant numbers of corticospinal 
axons over the first 24 postnatal months (Eyre et al., 2001), as has been observed in sub-human primates (Galea \& Darian-Smith, 1995) (Fig. 1 J-L; Fig. 6A). Furthermore, rapid differential development of the ipsilateral and contralateral projections occurs over this time so that responses at 2 years postnatal age in ipsi-lateral muscles are less frequent, significantly smaller, and have longer onset latencies and had
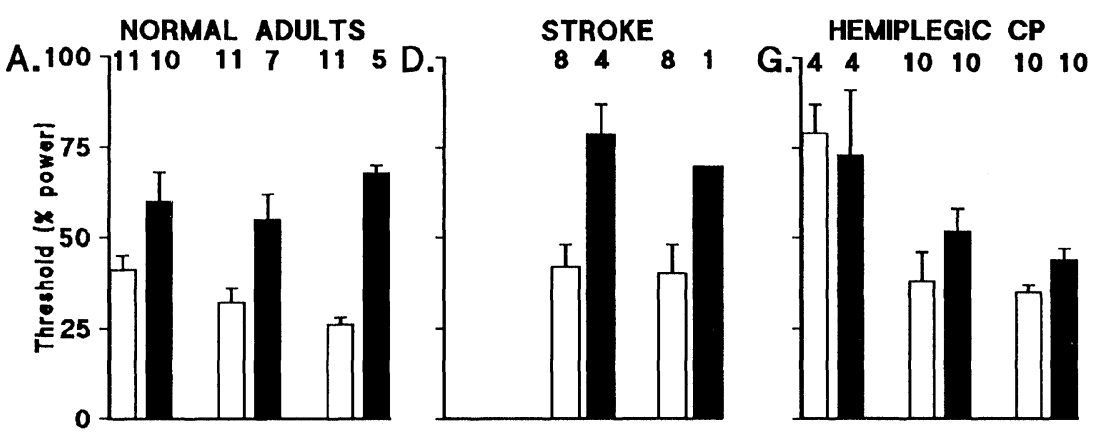

BICEPS: Age rolated norms

B. 25

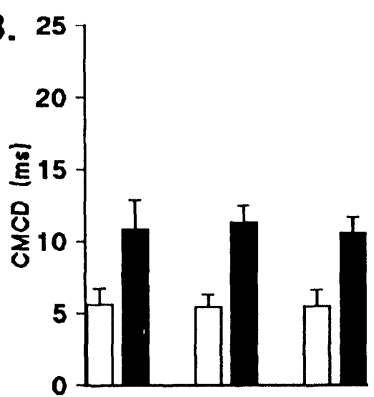

E.7.

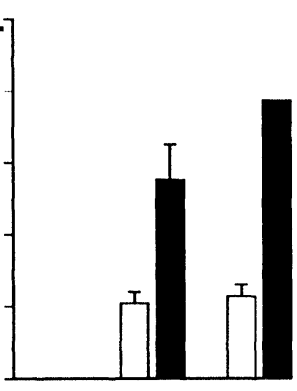

H.

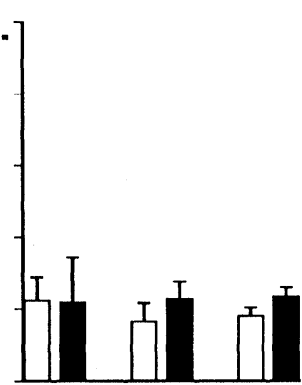

K.
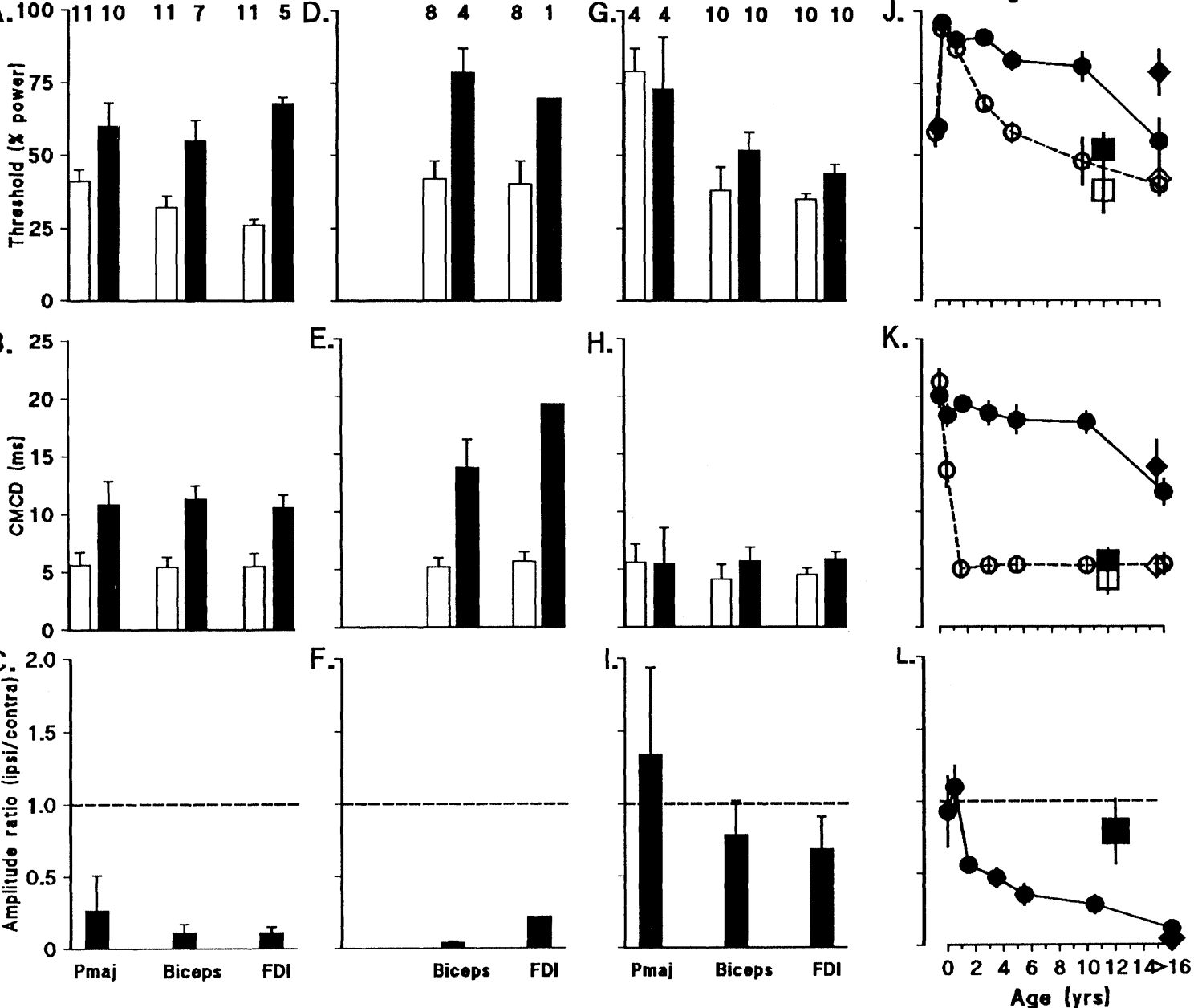

Fig. 1: A-1. Mean $\pm 95 \%$ confidence limits for threshold. A,D,G: Central motor conduction delay (CMCD) (B,E,H) and amplitude ratio $(\mathbf{C}, \mathbf{F}, \mathbf{I}))$ for ipsilateral responses $(\boldsymbol{\square})$ and contralateral responses $(\square)$ evoked by TMS of the left hemisphere in normal adults (A-C), and the intact hemisphere in subjects with hemiplegia following stroke (D-F) and those with spastic hemiplegic cerebral palsy (CP) (G-I). J-L: Ontogeny of ipsilateral and contralateral responses in biceps muscle. Data from a cross-sectional study of 84 subjects. TMS of the left cortex in normal subjects ?; TMS of the intact cortex in subjects with spastic hemiplegic cerebral palsy $;$; and subjects with stroke?. Filled symbols and continuous lines represent data from ipsilateral responses and open symbols and dashed lines contralateral. The symbols represent the mean, vertical lines $95 \%$ confidence limits. A,C,G,J: The threshold is measured as the percent of maximum stimulator output. The CMCD (B,E, $\mathbf{H}, \mathbf{K})$ is the central motor conduction delay within the corticospinal tract. The amplitude ratio $(\mathbf{C}, \mathbf{F}, \mathbf{I}, \mathbf{L}, \mathbf{)})$ was calculated by dividing the amplitude of the ipsilateral responses by that of the contralateral. The dashed horizontal line indicates a ratio of one where responses are of equal size. (from Eyre et al., 2001). 
higher thresholds than responses in contralateral muscles (Fig. $1 \mathrm{~J}$-L; Fig. 6A). This differential development of the ipsilateral responses is consistent with a grater withdrawal of ipsilateral corticomotoneuronal projections than contralateral, as has been observed during the development of the corticospinal tract in animals (Stanfield, 1992; Joosten et al., 1992). In addition, it is consistent with faster growth of axonal diameters in the contralateral corticospinal projection than in the ipsilateral projection (Fig. 2). The small and late ipsilateral responses observed in older children and adults are consistent with the persistence of a small ipsilateral corticomotoneuronal projection, with slower conducting axons than contralateral projections. This conclusion is supported by the results of anatomical studies in man and monkeys demonstrating that in maturity, the corticospinal tract has approximately 8 to 15 percent of uncrossed axons (Nathan et al., 1996). These ipsilaterally growing projecting axons have been shown in man and in non-human primates to arise from similar areas of the cortex and to have a similar pattern of spinal innervation to the contralateral projection (Liu \& Chambers, 1964; Nathan et al., 1996; Galea \& Darian-Smith, 1994).

Repeated observations in man have demonstrated substantial plastic reorganization of the motor cortex and corticospinal projections following prenatal or perinatal lesions to the corticospinal system (Benecke et al., 1991; Carr et al., 1993; Cao et al., 1993; Lewine et al., 1993; Maegaki et al., 1993; Terashima, 1995; Müller et al., 1997; Nirkko et al., 1997; Graveline et al., 1998; Balbi et al., 2000; Eyre et al., 2000a; 2001; Thick-broom et al., 2001). The findings of these studies are remarkably consistent with those made in animals following perinatal lesions to the corticospinal system. In children and adults who have suffered extensive damage to one motor cortex early in
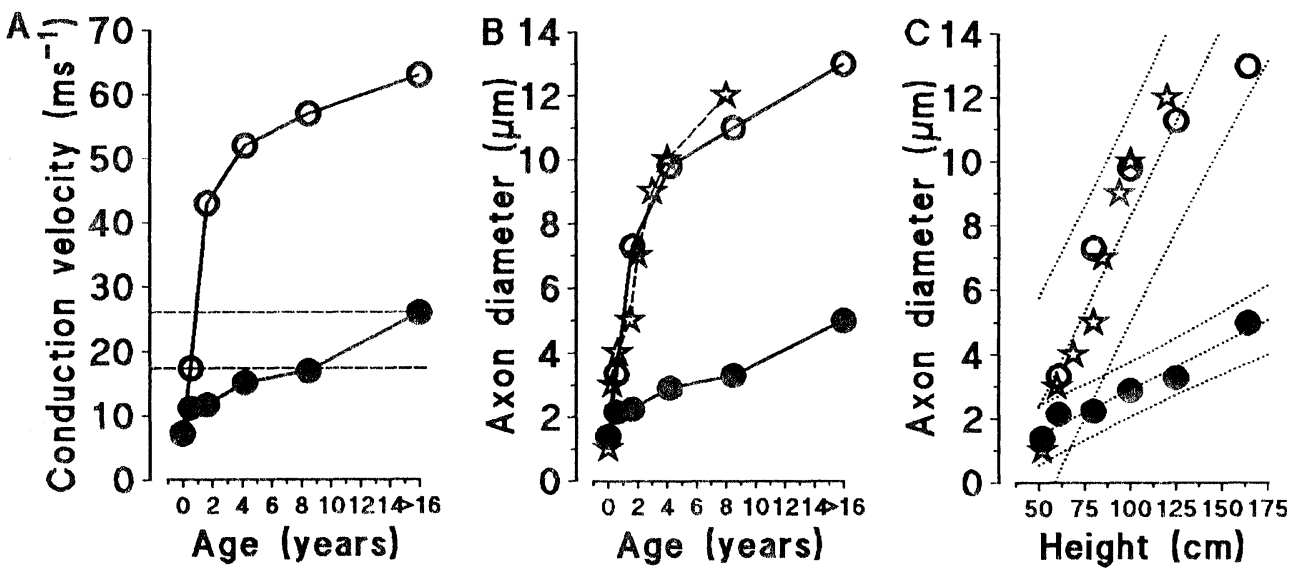

Fig. 2: A: Development of corticospinal axon conduction velocities in (o) contralateral and (?) ipsilateral corticospinal projections in man. The conduction velocities are estimated from central motor conduction delays (Eyre et al., 1999; Eyre et al., 2000b). B-C: Diameter of the largest corticospinal axons in human subjects in relation to age and mean body height. Open stars represent data obtained from by direct measurement at the level of the pyramid in a newborn baby and in subjects aged 4,8 , and 18 mos and 2, 3, 4, and 7 y, reported by Verhart (1950) and in a subject aged 13 y reported by Häggpvist (1937). Open and closed circles represent the respective mean axonal diameters in the contralateral and ipsilateral corticospinal tract. The axonal diameters were estimated from the conduction velocities of the subjects in $\mathbf{A}$ using the ratio of $5.2 \mathrm{~ms}^{-1} / \mu \mathrm{m} \mathrm{between}$ the conduction velocity of corticospinal axons and their diameters in the medullary pyramid (Olivier et al., 1997). 
development, significant bilateral corticospinal innervation of spinal motoneuronal pools persists from the undamaged hemisphere.

This focal TMS of the intact motor cortex evokes large responses in the ipsilateral and contralateral muscles, which have small latencies and thresholds (Figs. 1 and 3). These observations have been made following perinatal unilateral brain damage rising from a variety of pathologies, including infarction, dysplasia, and arteriovenous malformations (Benecke et al., 1991; Carr et al., 1993; Maegaki et al., 1993; Balbi et al., 2000; Eyre et al., 2000a; 2001; Thickbroom et al., 2001)

Short latency ipsilateral responses do not occur in normal subjects outside the perinatal period. Nor do they occur in subjects who acquired unilateral cortical lesions in adulthood, establishing that fast ipsilateral responses are not simply unmasked by unilateral lesions (Figs. 1 and 3) (Netz et al., 1997; Eyre et al., 2000). Furthermore, the

\section{Pmaj}

Biceps
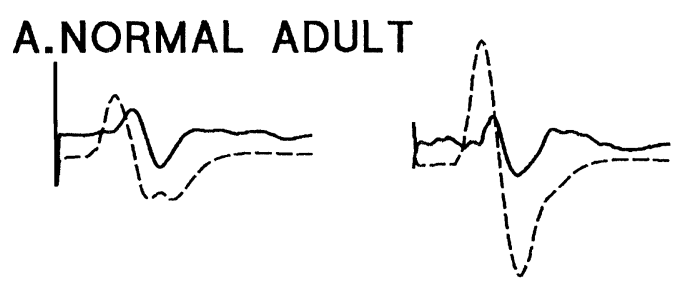

\section{B.STROKE}
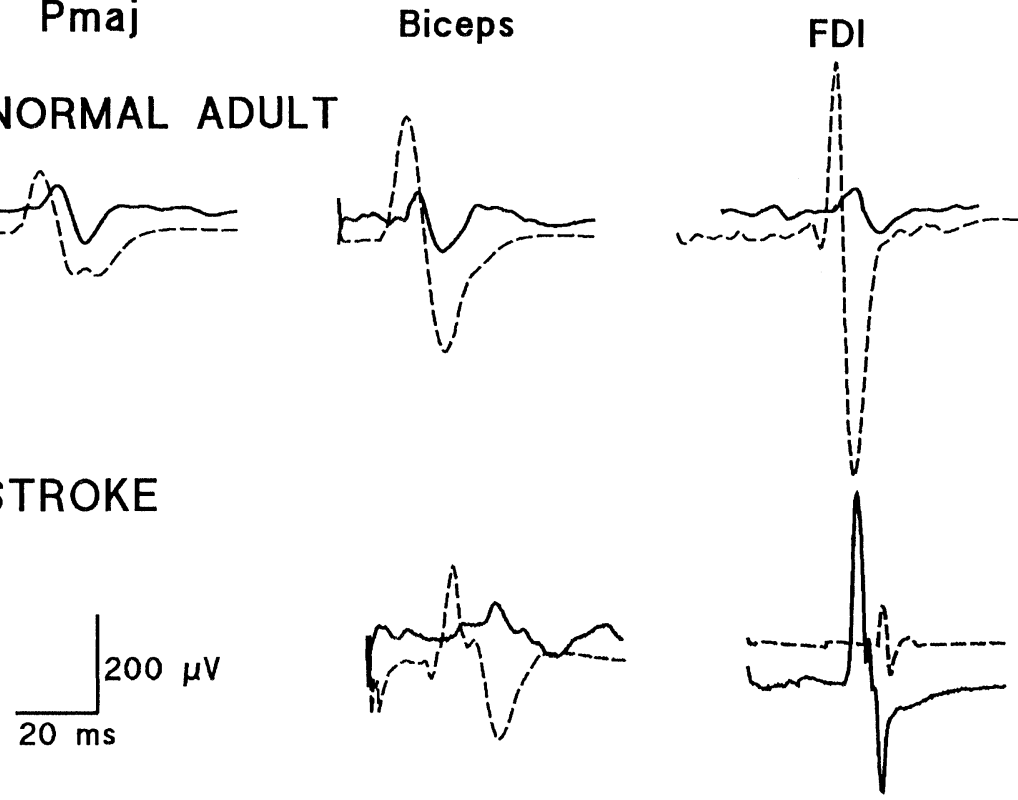

\section{CEREBRAL PALSY}
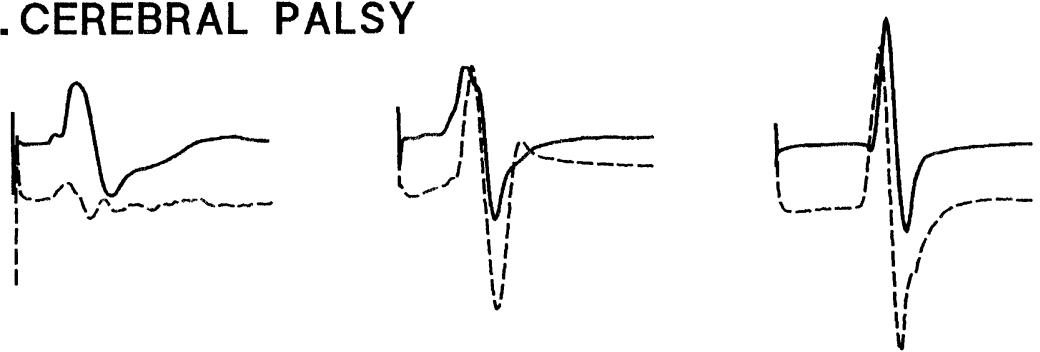

Fig. 3: Ipsilateral and contralateral responses recorded in the EMG of pectoralis major (Pmaj), biceps brachii (biceps), and the first dorsal interoseus muscle (FDI) following TMS of (A) the left hemisphere in a normal adult and the intact hemisphere in (B), a subject with stroke which occurred in adulthood, and (C), a subject with spastic hemiplegic cerebral palsy. The continuous traces in A, B, and C are from ipsilateral muscles and the dashed traces from contralateral muscles. TMS was delivered at the onset of each trace. (adapted from Eyre et al., 2001) 
responses in contralateral muscles evoked by stimulation of the intact motor cortex, although within the normal range for age are abnormally clustered toward short onset latencies and low thresholds (Fig. 1) (Eyre et al., 2001). Together these findings imply not only bilateral innervation of motoneuronal pools but also an increase in the number of both fast conducting ipsilateral and contralateral corticospinal axons from the intact hemisphere following perinatal unilateral lesions of the corticospinal system. This conclusion is supported by the direct measurement of corticospinal axonal number in the bulbar pyramidal obtained at post mortem. These measurements demonstrated significant increases in the number of corticospinal axons, particularly the larger diameter axons projecting from the intact hemi-sphere in adult subjects with spastic hemiplegic cerebral palsy in comparison with normal subjects and those with lesions acquired in childhood (Fig. 4) (Verhaart,

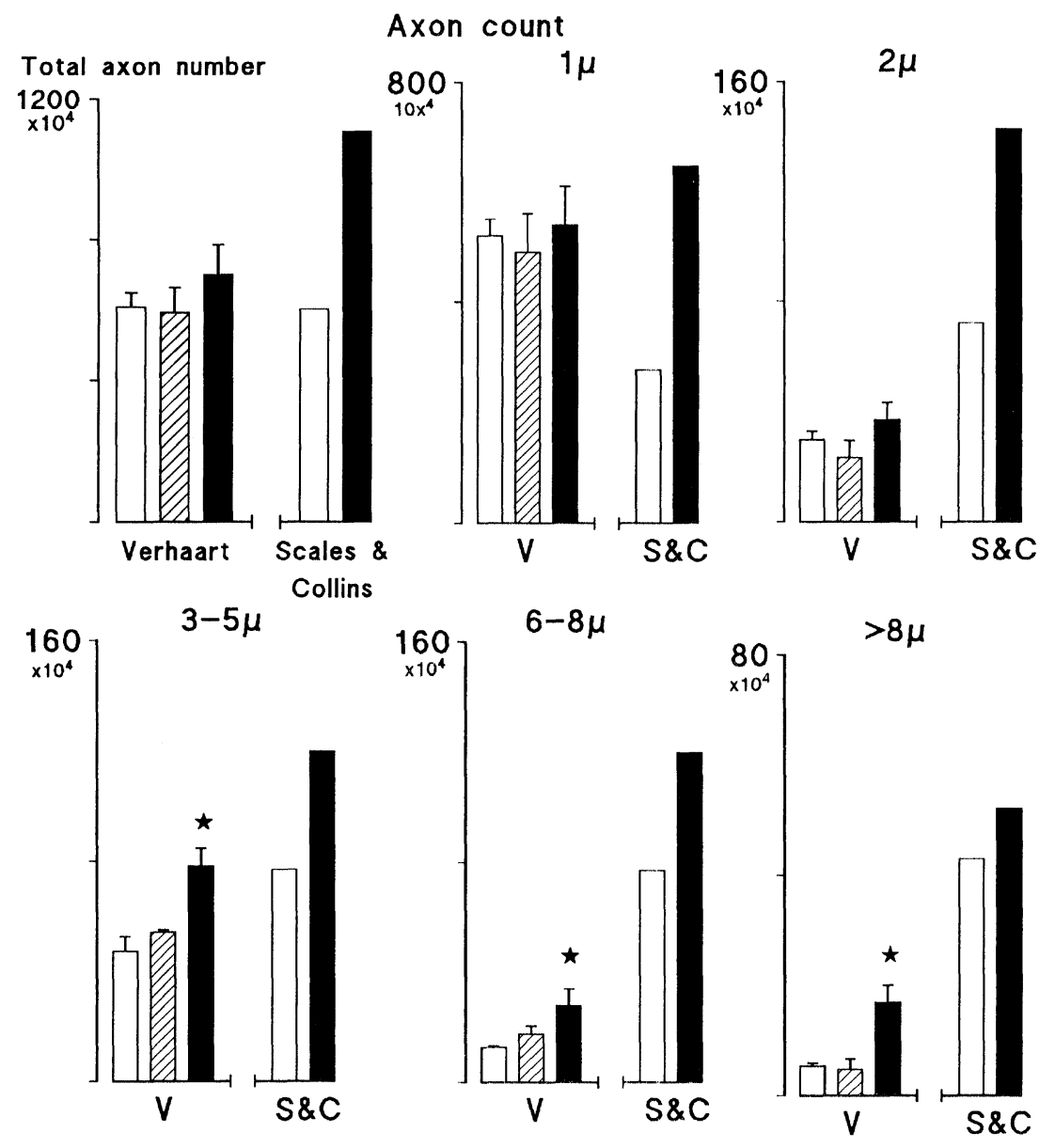

Fig. 4: Total axonal count and counts for axons of the specified diameters in the medullary pyramids in normal subjects and the medullary pyramid ipsilateral to the undamaged hemisphere in subjects with unilateral brain damage involving the motor cortex. Data from Verhar (1950) (V) who studied post mortem material from three normal

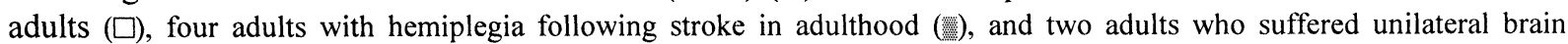
damage in the perinatal period $(\boldsymbol{\square})$. 
1950; Scales \& Collins, 1972). Similarly, MRI studies of subjects with early unilateral brain damage demonstrate an increased size of the corticospinal projection from and shift of cortical sensorimotor functions to the intact hemisphere (Cao et al., 1994; Lewine et al., 1994; Maegaki et al., 1995; Muller et al., 1995; Nirkko et al., 1997; Graveline et al., 1998; Muller et al., 1998; HertzPannier et al., 1999; Holloway et al., 1999; Wieser et al., 1999; Chu et al., 2000).

Finally, short onset ipsilateral responses observed bilaterally in subjects with Kallman's syndrome are associated with significant bilateral hyperplasia of the corticospinal tract (Mayston et al., 1997). Taken together, these observations support the persistence of ipsilateral and contralateral corticospinal projections from the intact hemisphere following unilateral brain damage early in development, which would normally have been withdrawn during subsequent development. While the results of some studies indicate that the increased ipsilateral corticospinal projections arise from the primary motor cortex of the intact hemisphere (Sabatini et al., 1994; Nirkko et al., 1997), a more common finding is of the projection arising from non primary motor and multimodal association areas of the non affected hemisphere (Pascual-Leone et al., 1992; Cao et al., 1994; Lewine et al., 1994; Muller et al., 1995; Graveline et al., 1998; Bernasconi et al., 2000; Bittar et al., 2000a; 2000b; Chu et al., 2000). These observations imply the maintenance of corticospinal projections from areas of the cortex where axons projecting to the spinal cord would normally have been withdrawn during development.

In our laboratory we observed different patterns of corticospinal system development after unilateral and bilateral lesions to the corticospinal tract. We compared the contralateral corticospinal projections in subjects with severe spastic hemiplegic and severe spastic quadriplegic cerebral palsy who had a similar severe pathology of hand and upper limb movement control (Eyre et al., 1989; 2000a; 2001). In the subjects with severe spastic hemiplegic cerebral palsy, TMS of the damaged cortex either failed to evoke responses or evoked responses with abnormally high thresholds and prolonged latencies. In contrast, response with relatively short onset latencies and low thresholds were evoked from the intact hemisphere. In subjects with spastic quadriparesis, response from both hemispheres lay predominantly within the normal range (Fig. 5).

These observations are consistent with a significant reduction in the corticospinal projection from damaged hemispheres and an increased projection from the intact hemisphere in subjects with unilateral lesions, while those with bilateral lesions maintain qualitatively normal projections from both hemispheres. An explanation for these apparently contradictory findings can be found in the studies of Martin and colleagues (Martin et al., 1999; Martin \& Lee, 1999). In the kitten, unilateral inhibition of the motor cortex causes exuberant ipsilateral and contralateral corticospinal projections from the uninhibited cortex to be maintained, at the expense of those from inhibited cortex, which becomes much reduced (Martin et al., 1999). Martin and his coworkers established that the reduction in inhibited contralateral projection whereas due to a competition between the two projections and not due to reduced activity per se, because in a subsequent experiment bilateral inhibition of the motor cortices led to qualitatively normal projections from both cortices (Martin \& Lee, 1999). Competitive-activity-dependent refinement of bilateral corticospinal projections demonstrates parallels between the mechanisms governing early postnatal development of the corticospinal system and that of the visual system. Monocular retinal activity blockade, for example, reduces the thalamic territory occupied by silenced retino-geniculate terminals and expands the active terminal's 
territory. By contrast, binocular activity blockade, which similarly inhibits interocular competition does not (Penn \& Shatz, 1999).

The activity-dependent competition between the two cerebral hemispheres for spinal synaptic space implies that the degree of abnormality of the corticospinal projection following unilateral lesions might not reflect simply the extent of the initial lesion but also the consequential competitive disadvantage of the surviving corticospinal projections. Such a competitive disadvantage would lead to corticospinal projections from the intact hemisphere progressively replacing the surviving corticospinal projections from the damaged

SPASTIC HEMIPARESIS SPASTIC QUADRIPARESIS

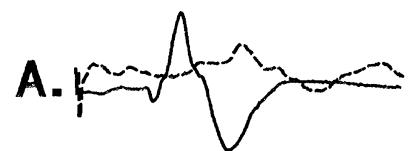<smiles>[R]C=CC=CC1CCCCCC1</smiles>

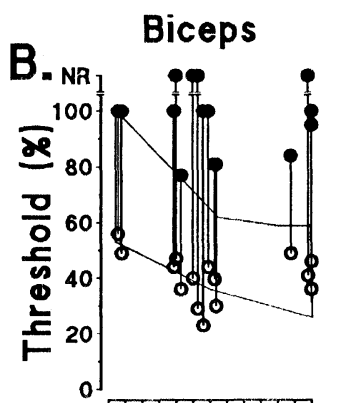

Hypothenar
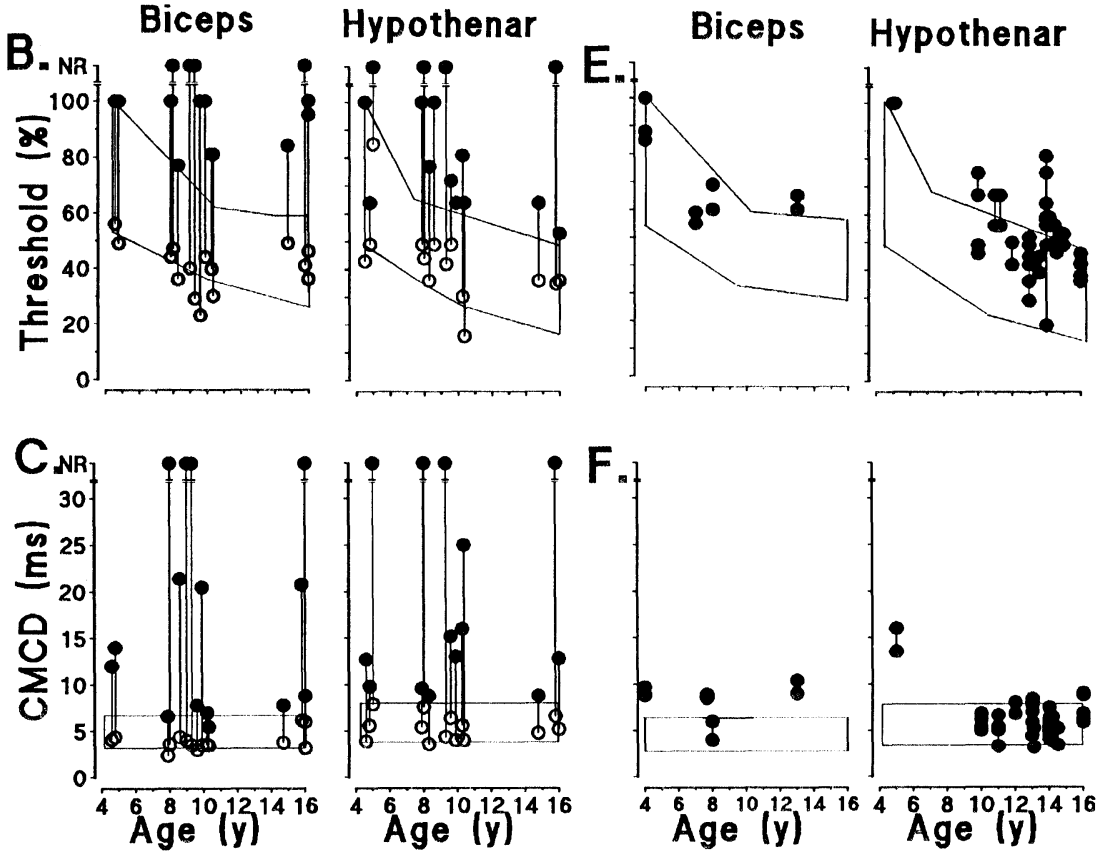

Fig. 5: (A) and (D). Contralateral responses evoked in biceps following TMS of the intact (continuous line) and lesioned (dashed line) motor cortices in (A), a subject with spastic hemiplegic cerebral palsy and (D), the left and right motor cortices in a subject with spastic quadriplegic cerebral palsy. TMS was applied at the start of each trace (adapted from Eyre et al., 1989). In graphs (B) (C) (E) (F), the vertical lines join the data from stimulation of each lesioned $(\bullet)$ and intact $(O)$ motor cortex in the same subject. The boxed areas represent the \pm 2 SD ranges for age obtained from in 372 normal subjects (Eyre et al., 1999). (B) and (E): Thresholds in subjects with spastic hemiplegic cerebral palsy and spastic quadriplegic cerebral palsy, respectively. Threshold is expressed as percent of maximum power delivered by the stimulator. $(\mathbf{C})$ and $(\mathbf{F})$ : Central motor conduction delay in the corticospinal tract $(\mathrm{CMCD})$ in subjects with spastic hemiplegic cerebral palsy and spastic quadriplegic cerebral palsy, respectively. $\mathrm{NR}=$ no response. 
hemisphere and thus to a progressively worsening hemiplegia with development. Recent observations in a longitudinal study of babies who have suffered a stroke at birth involving the motor cortex unilaterally support these conclusions (Smith Villagra \& Eyre, unpublished). Soon after birth we observed responses to TMS of the damaged cortex, which became progressively more difficult to elicit over the subsequent 3 to 6 months and which then disappeared. This pattern of development is associated with the rapid development in parallel of the contralateral and ipsilateral corticospinal projections from the undamaged hemisphere such that both have abnormally short onset latencies by 24 months of age (Fig. 6). This pattern of development is also consistent with the clinical observation that signs of hemiplegia might not become established in children until the end of the second year (Bouza et al., 1994). Our longitudinal study of the development of the corticospinal system following perinatal infarction (Smith Villagra \& Eyre, unpublished) also confirm the observations of Rouiller (1998) that the reorganization of the ipsilateral cortex can also occur with the functional resiting of the area of the motor cortex within the damaged hemisphere

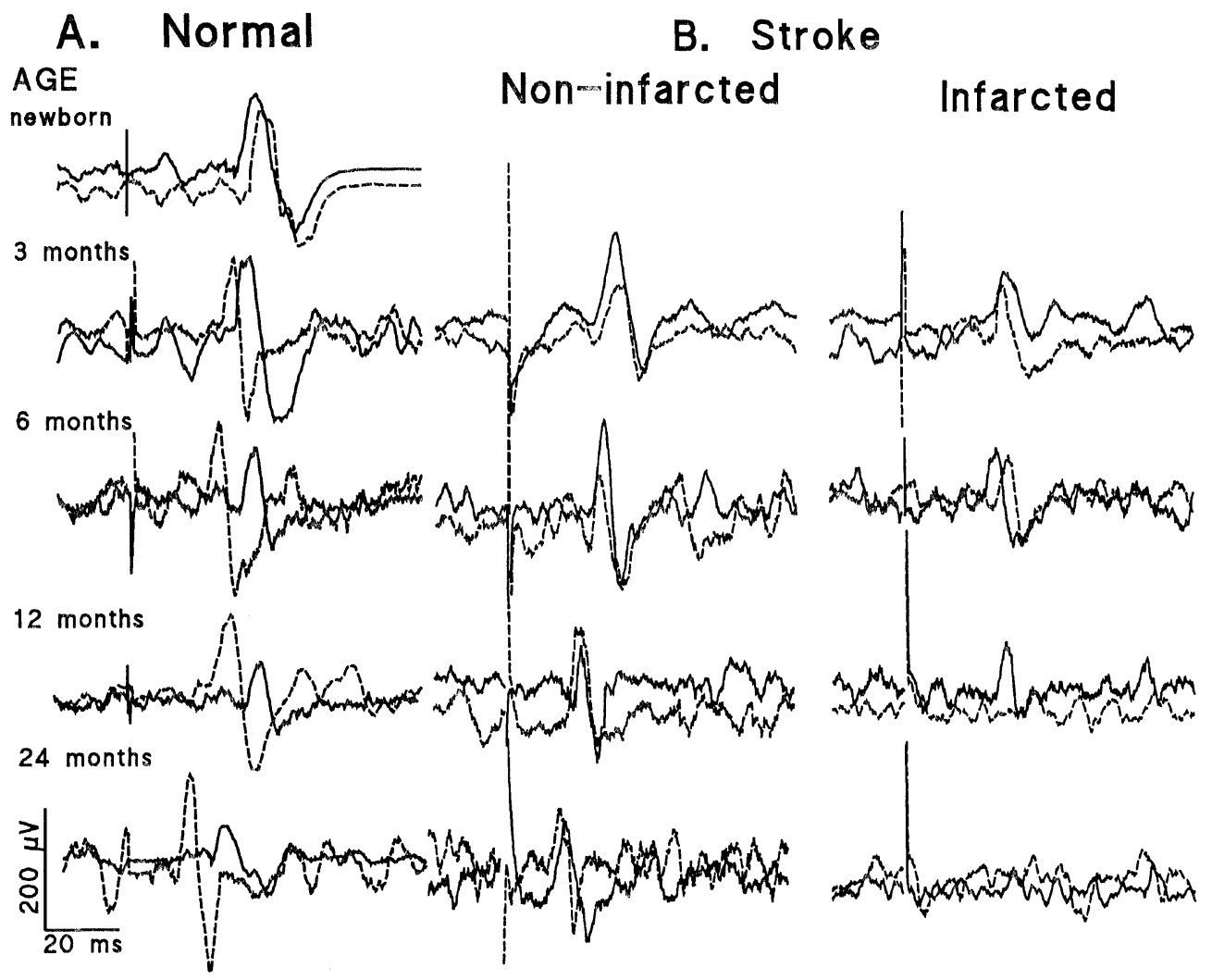

Fig. 6: Serial ipsilateral and contralateral responses recorded in the EMG of biceps at increasing ages following TMS of: (A) the left cortex in a normal subject and (B) the non-infarcted and infarcted hemisphere in a subject who suffered a unilateral stroke at birth. The continuous line traces are from biceps ipsilateral to the cortex stimulated and the dashed line traces are from the contralateral biceps. The stimulus artifact marks the application of TMS. 
(Alkadhi et al., 2000). This reorganization can be in the immediately adjacent areas of the primary motor cortex (Maegaki et al., 1995), within non primary motor areas (Alkadhi et al., 2000; Bittar et al., $2000 \mathrm{~b}$ ), and in other cases the reorganization of function can occur to more remote sites in the same hemisphere (Chollet et al., 1991). The exact factors that govern intrahemisphereric versus interhemispheric reorganization after sensorimotor lesions during development are not understood. It is likely that such reorganization is influenced by overall cortical development and specification at the time of the lesion, the fractional size of the lesion, the availability of sufficient and appropriate juxalesional cortex, the absence or presence of transient corticospinal projections (Martin et al., 1999; Martin \& Lee, 1999; Eyre et al., 2001), and the maturational status of the system as a whole at the time of the lesions (Eyre et al., 2000b).

The temporal limit of plasticity of both the ipsi- and contra-lesional motor cortices and their corticospinal projections is at present unknown. The existence of critical periods for substantial experience-dependent plasticity has been clearly demonstrated for the visual, auditory, and somatosensory systems and for language development in man. By starting periods of monocular deprivation at progressively older ages, Hubel and Wiesel (1970) first documented that ocular dominance plasticity is confined to a critical period, which in the cat extends from 3 weeks to about 3 months of age. Deprivationinduced plasticity occurs rapidly at the height of the critical period. In their original studies, Wiesel and Hubel monocularly deprived animals for months. A later work, they found that robust effects were observed with as little as a week of deprivation. Subsequent studies by many other investigators showed that as little as 8 hours of deprivation could produce synaptic depression in the visual cortex (Bear \& Rittenhouse, 1999). The neurophysiological consequences in animals are maximal after 48 hours of monocular deprivation at the height of the critical period. It is possible, therefore, that during critical periods, relatively short periods of relative inactivity of the motor cortex, induced by ischemia or over- activity induced by seizures, can lead to permanent plastic changes in the development of the motor cortex and corticospinal projections.

The observations on the plasticity of the corticospinal system in the perinatal period throw new light on "cerebral palsy", a term originally used by William Osler (1889) in the late nineteenth century to highlight the significant consequences on the motor development of lesions to the brain that occur in the perinatal period. It is likely that William Osler's seminal observations identify the perinatal period not only because of the special vulnerability of the motor system to damage at this time but also because abnormal or decreased activity in the corticospinal system during this critical perinatal period will secondarily disrupt the development of the motor cortex, corticospinal projections, and the spinal motor cortex.

Functional and anatomical evidence supports the view that spontaneous plasticity can be potentiated and shaped by activity. The sue of enriched environments and appropriately targeted training strategies are likely therefore to potentiate the capacity of the brain to compensate for lesioninduced deficits and allow relatively normal organized behavior. Pharmacological interventions and transplants of embryonic and fetal material are also likely to have important roles in the repair and regeneration of the corticospinal system during development. Understanding the development of plasticity of the corticospinal system is likely, therefore, to lead to treatments and interventions that maximize the functional outcome for children with cerebral palsy. 


\section{REFERENCES}

Alkadhi H, Kollias SS, Crelier GR, Golay X, HeppReymond MC, Valavanis A. 2000. Plasticity of the human motor cortex in patients with arteriovenous malformations: a functional MR imaging study. AJNR Am J Neuroradiol. 21: 1423-1433.

Balbi P, Trojano L, Ragno M, Perretti A, Santoro L. 2000. Patterns of motor control reorganization in a patient with mirror movements. Clin Neurophysiol 111: 318-325.

Barth TM, Stanfield BB. 1990. The recovery of forelimb-placing behavior in rats with neonatal unilateral cortical damage involves the remaining hemisphere. J Neurosci 10: 3449-3459.

Bear MF, Rittenhouse CD. 1999. Molecular basis for induction of ocular dominance plasticity. J Neurobiol 41: 83-91.

Benecke R, Meyer BU, Freund HJ. 1991. Reorganisation of descending motor pathways in patients after hemispherectomy and severe hemispheric lesions demonstrated by magnetic brain stimulation. Exp Brain Res 83: 419-426.

Bernasconi A, Bernasconi N, Lassonde M, Toussaint PJ, Meyer E, Reutens DC, et al. 2000. Sensorimotor organization in patients who have undergone hemispherectomy: a study with ${ }^{(15)} \mathrm{O}$ water PET and somatosensory evoked potentials. Neuroreport 11: 3085-3090.

Bouza H, Dubowitz LM, Rutherford M, Pennock JM. Prediction of outcome in children with congenital hemiplegia: a magnetic resonance imaging study. Neuropediatrics. 1994 Apr;25(2):60-6.

Bittar RG, Olivier A, Sadikot AF, Andermann F, Reutens DC. 2000a. Cortical motor and somatosensory representation: effect of cerebral lesions. J Neurosurg 92: 242-248.

Bittar RG, Ptito A, Reutens DC. 2000b. Somatosensory representation in patients who have undergone hemispherectomy: a functional magnetic resonance imaging study. J Neurosurg 92: 45-51.

Cao Y, Vikingstad EM, Huttenlocher PR, Towle VL, Levin DN. 1994. Functional magnetic resonance studies of the reorganization of the human hand sensorimotor area after unilateral brain injury in the perinatal period. Proc Natl Acad Sci USA 91: 9612-9616.

Carr LJ, Harrison LM, Evans AL, Stephens JA. 1993 Patterns of central motor reorganization in hemi- plegic cerebral palsy. Brain 116: 1223-1247.

Chollet F, DiPiero V, Wise RJ, Brooks DJ, Dolan RJ, Frackowiak RS. 1991. The functional anatomy of motor recovery after stroke in humans: a study with positron emission tomography. Ann Neurol 29: 63-71.

Chu D, Huttenlocher PR, Levin DN, Towle VL. 2000. Reorganization of the hand somatosensory cortex following perinatal unilateral brain injury. Neuropediatrics 31: 63-69.

Curfs MH, Gribnau AA, Dederen PJ. 1994. Selective elimination of transient corticospinal projections in the rat cervical spinal cord gray matter. Brain Res Dev Brain Res 78: 182-190.

Curfs MH, Gribnau AA, Dederen PJ. 1996. Direct cortico-motoneuronal synaptic contacts are present in the adult rat cervical spinal cord and are first established at postnatal day 7 . Neurosci Lett 205: 123-126.

Curfs MH, Gribnau AA, Dederen PJ, BergervoetVernooij HW. 1995. Transient functional connections between the developing corticospinal tract and cervical spinal interneurons as demonstrated by c-fos immunohistochemistry. Brain Res Dev Brain Res 87: 214-219.

Eyre JA, Gibson M, Koh T, Miller S. 1989. Corticospinal transmission excited by electromagnetic stimulation of the brain is impaired in children with spastic hemiparesis but not in those with quadriparesis. J Physiol 414: 9P.

Eyre JA, Taylor JP, Villagra F, Miller S. 2000a. Exuberant ipsilateral corticospinal projections are present in the human newborn and withdrawn during development probably involving an activity- dependent process.. Dev Med Child Neurol 82: 12 .

Eyre JA, Taylor JP, Villagra F, Smith M, Miller S. 2001. Evidence of activity-dependent withdrawal of corticospinal projections during human development. Neurology 57: 1543-1554.

Eyre JA, Miller S, Clowry GJ. 2002. The development of the corticospinal tract in humans. In: PascualLeone A, Davey NJ, Rothwell J., Wassermann, EM, Puri BK, eds, Handbook of Transcranial Magnetic Stimulation. Arnold: London; 235-249.

Eyre JA, Miller S, Clowry GJ, Conway EA, Watts C. 2000. Functional corticospinal projections are established prenatally in the human foetus permitting involvement in the development of spinal motor centres. Brain 123: 51-64. 
Eyre JA, Miller S, Ramesh V. 1991. Constancy of central conduction delays during development in man: investigation of motor and somatosensory pathways. J Physiol 434: 441-452.

Galea MP, Darian-Smith I. 1994. Multiple corticospinal neuron populations in the macaque monkey are specified by their unique cortical origins, spinal terminations, and connections. Cereb Cortex 4: 166-194.

Galea MP, Darian-Smith I. 1995. Postnatal maturation of the direct corticospinal projections in the macaque monkey. Cereb Cortex 5: 518-540.

Graveline CJ, Mikulis DJ, Crawley AP, Hwang PA. 1998. Regionalized sensorimotor plasticity after hemispherectomy fMRI evaluation. Pediatr Neurol 19: 337-342.

Hagan DM, Lisgo S, Strachan T, Davidson D, Baldock R, Stark M, et al. 1999. Mapping gene expression domains and neuronal cell differentiation during human embryonic forebrain development. Am J Hum Genet 65: 403. [abstract]

Häggqvist G. 1937. Faseranalytische studien uber dic pyramidenbahn. Acta Psychiatrica et Neurologica 12: 457-466.

Hertz-Palmer 1. 1999. Plasticite au cours de la maturation cerebrale: bases physogiques et etude IRM fontionelle. J Neuroradiol 26: IS66-IS74.

Hicks SP, D'Amato CJ. 1970. Motor-sensory and visual behavior after hemispherectomy in newborn and mature rats. Exp Neurol 29: 416438.

Hicks SP, D'Amato CJ. 1977. Locating corticospinal neurons by retrograde axonal transport of horseradish peroxidase. Exp Neurol 56: 410-420.

Holloway V, Chong WK, Connelly A, Harkness WH, Gadian DG. Somatomotor fMRI in the presurgical evaluation of a case of focal epilepsy. Clin Radiol 54: 301-303.

Hubel DH, Wiesel TN. 1972. Laminar and columnar distribution of geniculo-cortical fibers in the macaque monkey. J Comp Neurol 146: 421-450.

Humphrey T. 1960. The development of the pyramidal tracts in human fetuses correlated with cortical differentiation. In: Tower DB, Schade JB, eds, Structure and Function of the Cortex. Proceedings of the Second International Meeting of Neuro-biologists. Amsterdam, the Netherlands: Elsevier; 93-103.
Huttenlocher PR, Raichelson RM. 1989. Effects of neonatal hemispherectomy on location and number of corticospinal neurons in the rat. Brain Res Dev Brain Res 47: 59-69.

Jansen EM, Low WC. 1996. Quantitative analysis of contralateral hemisphere hypertrophy and sensorimotor performance in adult rats following unilateral neonatal ischemic-hypoxic brain injury. Brain Res 708: 93-99.

Joosten EA, Schuitman RL, Vermelis ME, Dederen PJ. 1992 Postnatal development of the ipsilateral cortico.spinal component in rat spinal cord: a light and electron microscopic anterograde HRP study. J Comp Neurol 326: 133-146.

Kartje-Tillotson G, Neafsey EJ, Castro AJ. 1985. Electrophysiological analysis of motor cortical plasticity after cortical lesions in newborn rats. Brain Res 332: 103-111.

Kartje-Tillotson G, O'Donoghue DL, Dauzvardis MF, Castro AJ. 1987. Pyramidotomy abolishes the abnormal movements evoked by intracortical micro- stimulation in adult rats that sustained neonatal cortical lesions. Brain Res. 415: 172177.

Leong SK. 1976. A qualitative electron microscopic investigation of the anomalous corticofugal projections following neonatal lesions in the albino rats. Brain Res 107: 1-8.

Lewine JD, Astur RS, Davis LE, Knight JE, Maclin EL, Orrison WW Jr. 1994. Cortical organization in adulthood is modified by neonatal infarct: a case study. Radiology 190: 93-96.

Liu C, Chambers W. 1964. An experimental study of the corticospinal system in the monkey. The spinal pathways and preterminal distribution of degener-ating fibres following discrete lesions of the pre- and postcentral gyri and bulbar pyramid. J Comp Neurol 123: 257-284.

Maegaki Y, Yamamoto T, Takeshita K. 1995. Plasticity of central motor and sensory pathways in a case of unilateral extensive cortical dysplasia: investigation of magnetic resonance imaging, transcranial magnetic stimulation, and shortlatency somatosensory evoked potentials. Neurology 45: 2255-2261.

Martin JH, Kably B, Hacking A. 1999. Activitydependent development of cortical axon terminations in the spinal cord and brain stem. Exp Brain Res 125: 184-199. 
Martin JH, Lee SJ. 1999. Activity-dependent competition between developing corticospinal terminations. Neuroreport 10: 2277-2282.

Mayston MJ, Harrison LM, Quinton R, Stephens JA, Krams M, Bouloux PM. 1997. Mirror movements in X-linked Kallmann's syndrome. I. A neurophysiological study. Brain 120: 1199-1216.

McClung JR, Castro AJ. 1975. An ultrastructural study of ipsilateral corticospinal terminations in the rat. Brain Res 89: 327-330.

Muller RA, Rothermel RD, Behen ME, Muzik O, Chakraborty PK, Chugani HT. 1997. Plasticity of motor organization in children and adults. Neuroreport 8: 3103-3108.

Muller RA, Watson CE, Muzik O, Chakraborty PK, Chugani HT. 1998. Motor organization after early middle cerebràl artery stroke: a PET study. Pediatr Neurol 19: 294-298.

Nathan PW, Smith M, Deacon P. 1996. Vestibulospinal, reticulospinal and descending propriospinal nerve fibres in man. Brain 119: 18091833.

Netz J, Lammers T, Homberg V. 1997. Reorganization of motor output in the nonaffected hemisphere after stroke. Brain 120: 1579-1586.

Olivier E, Edgley SA, Ármand J, Lemon RN. 1997. An electrophysiological study of the postnatal development of the corticospinal system in the macaque monkey. J Neurosci 17: 267276.

O'Rahilly R, Muller F. 1994. Human embryonic brain. An Atlas of Developmental Stages. New York, NY, USA: Wiley-Liss.

Osler W. 1889. The cerebral palsies of children. A Clinical Study from the Infirmary for Nervous Diseases. Philadelphia, Pennsylvania, USA: Blakiston, Son \& Co.

O'Sullivan MC, Miller S, Ramesh V, Conway E, Gilfillan K, McDonough S, Eyre JA. 1998. Abnormal development of biceps brachii phasic stretch reflex and persistence of short latency heteronymous reflexes from biceps to triceps brachii in spastic cerebral palsy. Brain 121: 2381-2395.

Oudega M, Varon S, Hagg T. 1994. Distribution of corticospinal motor neurons in the postnatal rat: quantitative evidence for massive collateral elimination and modest cell death. J Comp Neurol 347: 115-126.
Pascual-Leone A, Chugani H, Cohen LG. 1992. Reorganization of human cortical motor pathways following hemispherectomy. Ann Neurol 32: 261.

Payne BR, Lomber SG. 2001. Reconstructing functional systems after lesions of cerebral cortex. Nat Rev Neurosci 2: 911-919.

Penn AA, Shatz CJ. 1999. Brain waves and brain wiring: the role of endogenous and sensory-driven neural activity in development. Pediatr Res 45: 447-458.

Raineteau O, Schwab ME. 2001. Plasticity of motor systems after incomplete spinal cord injury. Nat Rev Neurosci 24: 263-273.

Reinoso BS, Castro AJ. 1989. A study of corticospinal remodelling using retrograde fluorescent tracers in rats. Exp Brain Res 74: 387-394.

Rouiller EM, Yu XH, Moret V, Tempini A, Wiesendanger M, Liang F. 1998. Dexterity in adult monkeys following early lesion of the motor cortical hand area: the role of cortex adjacent to the lesion. Eur J Neurosci 10: 729-740.

Sabatini U, Toni D, Pantano P, Brughitta G, Padovani A, Bozzao L, Lenzi GL. 1994. Motor recovery after early brain damage. A case of brain plasticity. Stroke 25: 514-517.

Scales DA, Collins GH. 1972. Cerebral degeneration with hypertrophy of the contralateral pyramid. Arch Neurol 26: 186-190.

Stanfield BB. 1992. The development of the corticospinal projection. Prog Neurobiol 38: 169-202.

Stanfield BB, O'Leary DD. 1985. The transient cortico- spinal projection from the occipital cortex during the postnatal development of the rat. J Comp Neurol 238: 236-248.

Stanfield BB, O'Leary DD, Fricks C. 1982. Selective collateral elimination in early postnatal development restricts cortical distribution of rat pyramidal tract neurons. Nature 298(5872): 371373.

Terashima T. 1995. Anatomy, development and lesion- induced plasticity of rodent corticospinal tract. Neurosci Res 22: 139-161.

Thickbroom GW, Byrnes ML, Archer SA, Nagarajan L, Mastaglia FL. 2001. Differences in sensory and motor cortical organization following brain injury early in life. Ann Neurol 49: 320-327.

Uematsu J, Ono K, Yamano T, Shimada M. 1996. Development of corticospinal tract fibers and their plasticity. II. Neonatal unilateral cortical damage 
and subsequent development of the corticospinal tract in mice. Brain Dev 18: 173-178.

Verhaart WJC. 1950. Hypertrophy of pes pedunculi and pyramid as result of degeneration of contralateral corticofugal fiber tracts. J Comp Neurol 92: 1-15.
Wieser HG, Henke K, Zumsteg D, Taub E, Yonekawa Y, Buck A. 1999. Activation of the left motor cortex during left leg movements after right central resection. J Neurol Neurosurg Psychiatry 67: 487491 

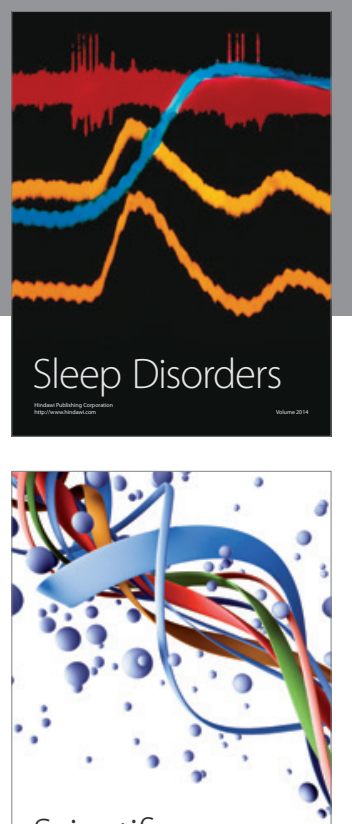

Scientifica
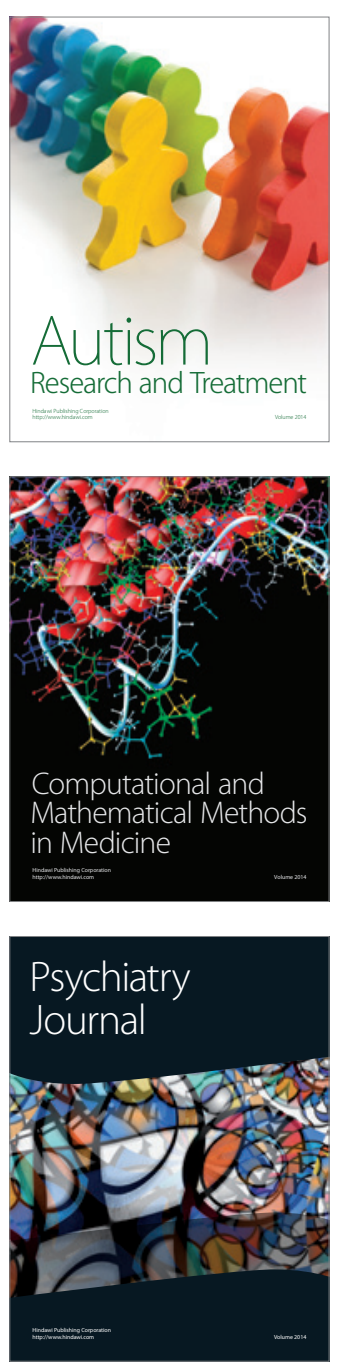
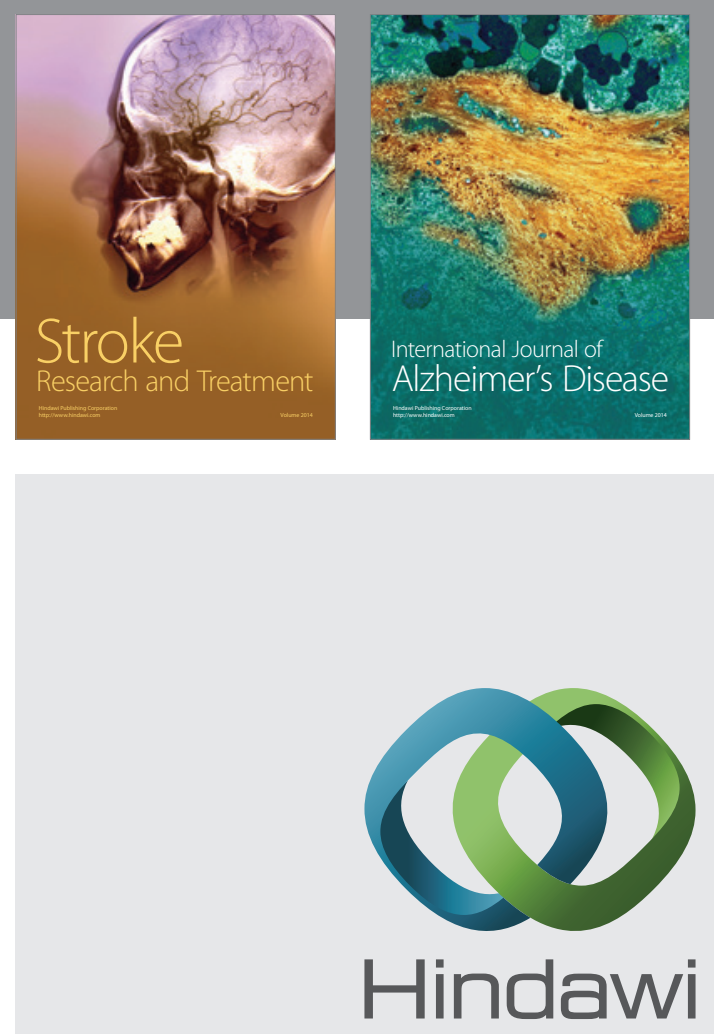

Submit your manuscripts at

http://www.hindawi.com
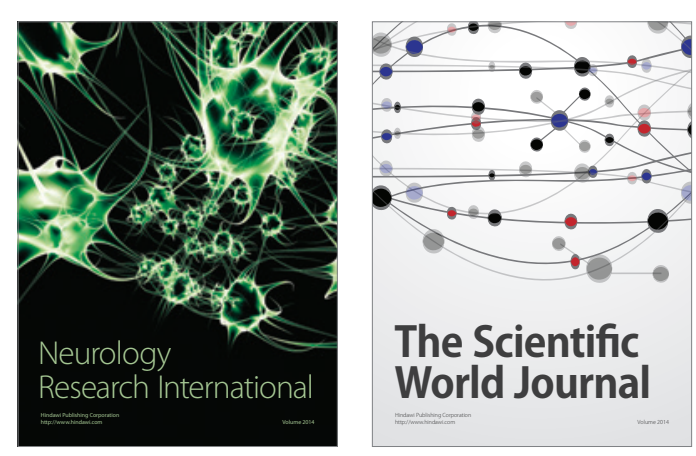

The Scientific World Journal

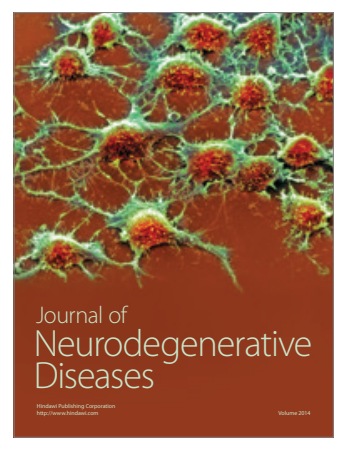

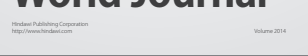

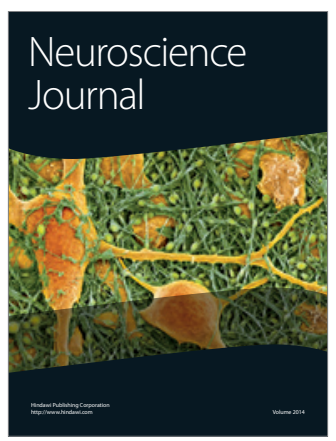

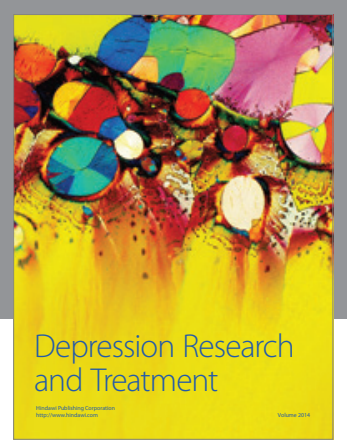
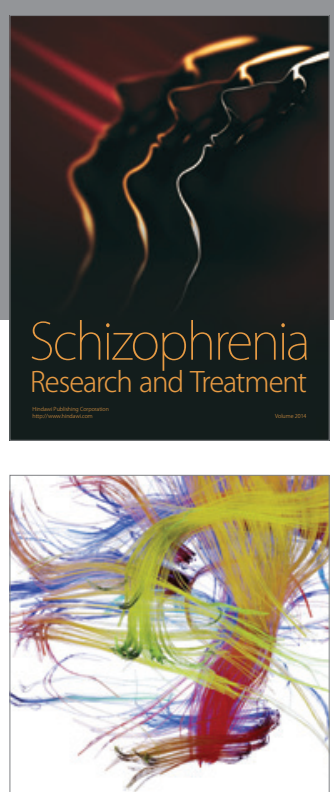

Brain Science

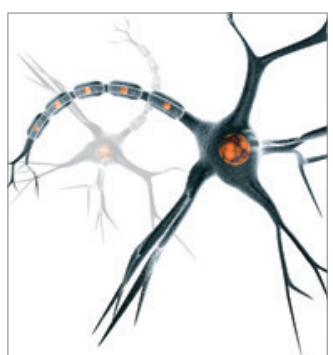

Neural Plasticity
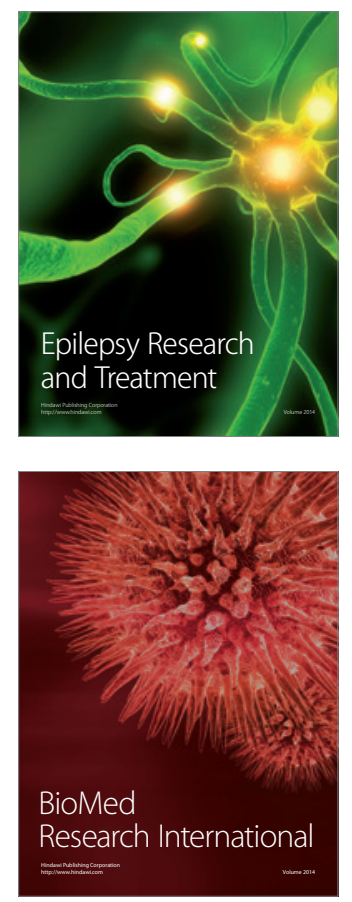

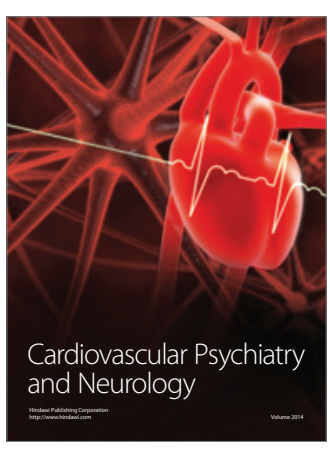

Parkinson's

Disease
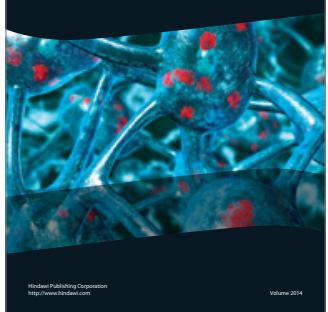